\title{
On the use of mass-conserving wind fields in chemistry-transport models
}

\author{
B. Bregman ${ }^{1}$, A. Segers ${ }^{1}$, M. Krol ${ }^{2}$, E. Meijer ${ }^{1}$, and P. van Velthoven ${ }^{1}$ \\ ${ }^{1}$ Royal Netherlands Meteorological Institute, P.O. Box 201, 3730 AE, De Bilt, The Netherlands \\ ${ }^{2}$ Institute for Marine and Atmospheric Research Utrecht, Princetonplein 5, 3584 CC, The Netherlands \\ Received: 30 August 2002 - Published in Atmos. Chem. Phys. Discuss.: 28 October 2002 \\ Revised: 22 January 2003 - Accepted: 8 April 2003 - Published: 15 April 2003
}

\begin{abstract}
A new method has been developed that provides mass-conserving wind fields for global chemistry-transport models. In previous global Eulerian modeling studies a mass-imbalance was found between the model mass transport and the surface pressure tendencies. Several methods have been suggested to correct for this imbalance, but so far no satisfactory solution has been found. Our new method solves these problems by using the wind fields in a spherical harmonical form (divergence and vorticity) by mimicing the physics of the weather forecast model as closely as possible. A 3-D chemistry-transport model was used to show that the calculated ozone fields with the new processing method agree remarkably better with ozone observations in the upper troposphere and lower stratosphere. In addition, the calculated age of air in the lower stratosphere show better agreement with observations, although the air remains still too young in the extra-tropical stratosphere.
\end{abstract}

\section{Introduction}

Mass conservation is a fundamental requirement in global model integrations, both in chemistry-transport models (CTMs), which use external meteorological fields (the "offline" mode), and in general circulation models (GCMs), in which the transport is calculated ("on-line" mode). Changes in surface pressure should be consistent with the air mass changes within the model. However, in most models the vertically integrated mass change is not in balance with the surface pressure during a model time step, so that the fluxes need to be corrected. In most GCMs wind vectors are used to drive the transport of air, rather than mass. The wind vectors need to be transformed to mass fluxes. This has been recognized as the mass imbalance problem (Heimann and Keeling,

Correspondence to: B. Bregman (bregman@knmi.nl)
1989; Jöckel et al., 2001), which is caused by the following reasons.

- The mass fluxes and surface pressure fields are independently calculated so that mass changes in the model do not necessarily balance the surface pressure tendency. This is the most fundamental point and applies to any primitive equation in GCMs or CTMs that use GCM output directly. Note that the GCMs (like the ECWMF model) do not conserve mass over multi-month integrations for this reason, and a small correction is applied to maintain global average surface pressure.

- The calculated mass fluxes that drive the CTM should mimic the GCM fluxes closely. In case of using ECWMF winds in the CTM, mass imbalance arises if the continuity equation in hybrid $\sigma$-pressure coordinates is not used in the flux form and the divergence, vorticity and surface pressure are interpolated from the spectral representation, instead of being transformed directly onto a grid. Below we will outline different methods to achieve such a transformation.

- The differences between model integration time intervals and the discrete time steps at which meteorological fields are available. This inevitably leads to mass imbalance, and generally applies to models that use external meteorological fields. Weather forecast models produce analysis fields which are a mixture of the model predictions and observations.

The reader is referred to Jöckel et al. (2001) for a detailed overview of potential causes of mass inconsistence in global chemistry-transport and climate models.

Various correction methods have been employed to achieve mass balance. Stockwell and Chipperfield (1999) applied a local tracer mass correction at hybrid $\sigma$-pressure layers. Jöckel et al. (2001) suggested a two-step model grid 
adjustment to correct for the mass imbalance in the global 3-D CTM MATCH. They demonstrated that no corrections lead to unrealistic tracer distributions, but that corrections may also lead to (spurious) variations in tracer concentrations, particularly in the case of pronounced vertical gradients. Their conclusion was that the problem could potentially be remedied with advection in the flux form or, in case of an off-line model, with GCM air mass fluxes instead of velocities.

Heimann and Keeling (1989) and Heimann (1995) recognized this problem and applied corrections in the most consistent way by utilizing a mass-flux advection scheme in their 3-D CTM, tracer model version 2 (TM2) and mass fluxes from ECWMF. The correction method they applied is referred to in this work as the 'old' method and described in more detail in Sect. 2.

Bregman et al. (2001) also used this correction method in the next version of the tracer model (TM3). However, they found significantly higher modeled ozone fields in the lower(most) stratosphere than observed, which they attributed partly to errors in the mass fluxes by interpolation of the spectral meteorological fields to the Cartesian model grid (the second cause mentioned in the first paragraph). To solve this, they included the vertical mass fluxes directly from the meteorological fields and corrected the horizontal mass fluxes accordingly. This gave much better agreement with observations in the winter, but worse in summer. Moreover, this correction method could not be applied at pressure levels higher than $300 \mathrm{hPa}$. Therefore another solution had to be found.

In this work we report a new method for mass flux processing to solve the mass-imbalance problem. This method is designed for CTMs and GCMs and minimizes interpolation errors by integrating the spectral divergence, vorticity and surface pressure following Simmons and Burridge (1981). It further accounts for surface pressure changes for every model layer in a consistent manner (Segers et al., 2002).

We have performed two types of model experiments to evaluate the processing method. One involves the calculation of the mean age of air, and the second consists of integrations with an ozone tracer version of the model. We will show that, by using the new method, both the observed age of air and ozone fields are significantly better represented by the model.

In the following section we describe the tracer model and the old and new mass flux processing methods. Section 3 contains a description of the model experiment and presents the results of the model evaluation. The vertical air mass fluxes have been analyzed in Sect. 4 to explain the model results. This is followed by conclusions.

\section{Model description}

The global Tracer Model Version 3 (TM3) used in this study is a grid point 3-D Chemistry-Transport Model (CTM), originally developed by Heimann (1995); Heimann and Keeling (1989). Different versions of TM3 have been developed and validated recently (Dentener et al., 1999; Peters et al., 2001; Houweling et al., 1998; Van den Broek et al., 2000) 6-Hourly forecasts of the European Centre for Medium-range Weather Forecasts (ECMWF) are used to drive the transport. The model contains a Cartesian grid with a horizontal resolution of $2.5^{\circ} \times 2.5^{\circ}$. It further contains 31 hybrid $\sigma$-pressure levels with the top level at $10 \mathrm{hPa}$. The vertical resolution varies with altitude, being hundred to a few hundred meters in the troposphere, one kilometer around the tropopause gradually increasing to a few kilometers close to the model top. The tracers are advected using second-order moments (Prather, 1986). More detailed model description can be found elsewhere (Bregman et al., 2001).

The processing of the mass fluxes is performed using the 'old' and 'new' method, described in the following subsections.

\subsection{Old method}

In the old processing method the horizontal mass fluxes were derived from ECMWF spectral data, gridded on a $1^{\circ} \times 1^{\circ}$ resolution. The horizontal mass fluxes $\left[\mathrm{kg} \mathrm{s}^{-1}\right], \boldsymbol{\Phi}_{h}=$ $\left(\Phi_{u}, \Phi_{v}\right)$ are balanced with the surface pressure tendency by adding 'small' correction fluxes $\boldsymbol{F}=\left(F_{u}, F_{v}\right)$, to the vertically integrated horizontal mass fluxes shown in Eq. (1):

$\boldsymbol{\delta}_{h} \cdot \boldsymbol{F}=-\left[m_{s}\left(t_{1}\right)-m_{s}\left(t_{0}\right)\right] / \Delta t-\sum_{k=1}^{n l e v}\left[\boldsymbol{\delta}_{h} \cdot \boldsymbol{\Phi}_{h}(k)\right]$

with $\mathrm{m}_{s}$ the air mass $[\mathrm{kg}]$ representative for the grid column, defined by the surface pressure $p_{s}$, the grid cell area $(A)$, and the acceleration gravity $g\left(m_{s}=p_{s} A / g\right) . \boldsymbol{\delta}_{h} \boldsymbol{\Phi}_{h}(k)$ is the net mass flux across a grid cell in the zonal and meridional direction at layer $k$.

The correction field, $\boldsymbol{F}$, needed for mass balance is calculated by changing Eq. (1) into a Poisson equation, which is solved by discrete Fourier Transform (Heimann and Keeling, 1989; Heimann, 1995) (see also Segers et al., 2002, for details). $\quad \boldsymbol{F}$ is distributed over the vertical grid layers, $l$, weighted arbitrarily with the magnitude of the uncorrected horizontal mass fluxes. By this method errors in the horizontal mass fluxes arise due to (i) interpolation and (ii) the arbitrarily vertical distribution of $\boldsymbol{F}$, which lacks a realistic physical interpretation.

\subsection{New method}

In the new processing method the above mentioned problems have been solved. For mass balance the divergence, vorticity, and surface pressure are needed. For the surface pressure 
we have used the natural $\operatorname{logarithm}\left(\ln p_{s}\right)$, since this is used by the ECMWF model. The new processing method requires that these quantities are retrieved in the original model representation, i.e. in spherical harmonics. The method is essentially the same as used in the ECWMF model (Simmons and Burridge, 1981), and is described in detail by Segers et al. (2002).

The horizontal mass fluxes $\left[\mathrm{kg} \mathrm{s}^{-1}\right], \boldsymbol{\Phi}_{h}=\left(\Phi_{u}, \Phi_{v}\right)$ are obtained by integrating the spectral fields over the grid cell boundaries in the following equations.

$$
\begin{aligned}
& \Phi_{u}=\frac{R}{g} \int_{\Delta \beta_{i}} \frac{U(\lambda, \beta, k)}{\cos \beta} \Delta p_{k} \mathrm{~d} \beta \\
& \Phi_{v}=\frac{R}{g} \int_{\Delta \lambda_{i}} V(\lambda, \beta, k) \Delta p_{k} \mathrm{~d} \lambda
\end{aligned}
$$

In here, $\lambda$ is the longitude, $\beta$ the latitude, $\Delta p_{k}=\Delta a_{k}+$ $\Delta b_{k} p_{s}$ the pressure difference over a model layer $k$ with $a_{k}$ and $b_{k}$ the hybrid coefficients, and $(U, V)=(u, v) \cos \beta$, a scaled velocity vector. The latter is easy to compute in spectral form from spectral vorticity and divergence. $R$ represents the radius of the earth $[\mathrm{m}]$ and $g$ the acceleration of gravity.

As described above, these mass fluxes should be consistent with the mass tendency obtained from the surface pressures $p_{s}[\mathrm{~Pa}]$, which are calculated from their spectral representation by surface integration over the grid cell.

The vertical mass fluxes $\boldsymbol{\Phi}_{w}\left[\mathrm{~kg} \mathrm{~s}^{-1}\right]$ for a level $k$ are calculated by vertical integration of the mass divergence and pressure gradients in Eqs. (4) and (5).

$\Phi_{w}=\frac{R^{2}}{g} \iint_{A_{i}}\left[\left(\sum_{j=1}^{n_{l e v}} \Omega_{j}\right) b_{k+1 / 2}-\sum_{j=1}^{k} \Omega_{j}\right] \cos \beta \mathrm{d} \beta \mathrm{d} \lambda$

where

$\Omega_{j}=D_{j}\left(\Delta a_{j}+\Delta b_{j} p_{s}\right)+\frac{\boldsymbol{V}_{j}}{\cos \beta} \cdot\left(\nabla\left(\ln p_{s}\right)\right) p_{s} \Delta b_{j}(5)$

Here $\Omega=\nabla \cdot(\boldsymbol{v} \cdot \Delta p)$ and represents the horizontal mass divergence $\left[\mathrm{kg} \mathrm{s}^{-1}\right]$. It is computed from the 'velocity divergence' $D_{j}=\nabla \cdot \boldsymbol{v}\left[s^{-1}\right]$, and the horizontal gradient of the surface pressure $\left(\nabla \ln p_{s}\right)$. The latter arises because of orography and is relevant for models with vertical hybrid $\sigma$ pressure levels. For models with plain pressure levels the second term on the right in Eq. (5) can be omitted, since $\Delta b_{j}$ $=0$. $\nabla \ln p_{s}$ can also be derived from $\ln p_{s}$ in spectral representation.

After expansion into Legendre functions (Eq. 5 in Segers et al., 2002), the spectral fields are integrated numerically over the grid cell boundaries (for horizontal fluxes) or grid cell area (for average surface pressure and vertical flux).

A small mass imbalance is still present between the mass tendency and the calculated vertical and horizontal mass fluxes, since the meteorological fields represent a discrete

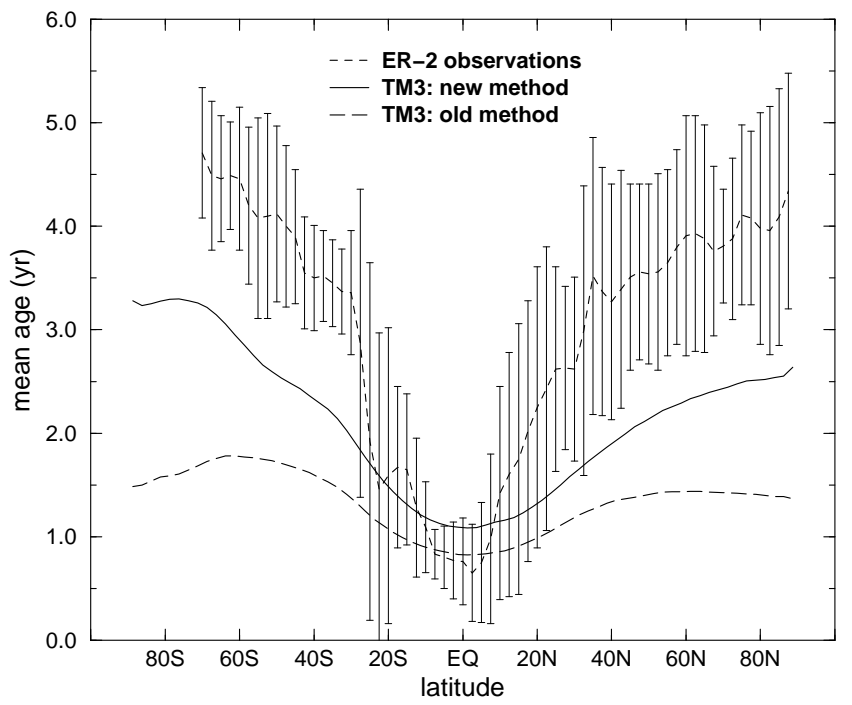

Fig. 1. Observed mean age of air at $20 \mathrm{~km}$ altitude, compiled from all ER-2 $\mathrm{CO}_{2}$ data from 1992 and 1998 (solid line), including the error bars $( \pm 2 \sigma)$ (Andrews et al., 2001). The model results are shown by the dashed (old method) and solid (new method) lines.

time condition. To obtain mass fluxes that are in balance with the mass tendency over the considered time interval, a correction flux $\boldsymbol{F}_{k}$ is obtained. This correction flux is computed independently for each layer $k$, in a way similar to the old procedure, and is added to the horizontal fluxes in equation 6 .

$\boldsymbol{\delta}_{h} \cdot \boldsymbol{F}_{k}=-\left[m_{k}\left(t_{1}\right)-m_{k}\left(t_{0}\right)\right] / \Delta t-\boldsymbol{\delta}_{h} \cdot \boldsymbol{\Phi}_{h}(l)-\delta_{k} \Phi_{w}(l)(6)$

with $\delta_{k}$ as the vertical difference operator (see also Eqs. 15 and 16 in Segers et al., 2002). Note that now $\delta_{k} \Phi_{w}$ is explicitly included, representing the net vertical mass flux for every vertical layer, $k$.

\section{Model evaluation}

We have performed model experiments with two different versions of the TM3 model to evaluate the mass flux processing methods. First we calculated the mean age of air in the stratosphere with a tracer-pulse experiment. Next, we simulated a realistic ozone distribution by integrations of the TM3 ozone tracer version. By calculating the mean age of air the large-scale circulation is examined. The ozone tracer experiment allows us to test the model performance on shorter time scales in regions with large tracer gradients and strong dynamical mixing. The model results have been compared with in situ observations.

\subsection{Mean age of air experiment}

The age spectrum, formally developed by Hall and Plumb (1994), is the probability distribution function of transit times 
of parcels from a source region to the sample region. This concept has shown to be a useful diagnostic for evaluating transport processes in global models (Hall et al., 1999). However, caution must be taken if a model evaluation relies on the mean age of air only, since artifacts in different aspects of the circulation, which are not present in the mean age, may compensate (Schoeberl et al., 2002).

With a global transport model (CTM or GCM) the age spectrum is directly obtained from a passive tracer simulation where the mixing ratio in a small tropospheric volume is set equal to a delta-function in time. The source volume is located between $10^{\circ} \mathrm{S}$ and $10^{\circ} \mathrm{N}$ in the lowest 8 model layers, up to about $800 \mathrm{hPa}$, where the initial mixing ratio was set to one during the first model time step and zero hereafter. The response is then simply the age spectrum (Hall and Waugh, 1997). To allow the model to reach a stationary tracer distribution, the total simulation time was continued for 20 years, using the ECMWF meteorology of 1996 repeatedly.

Note that the mean age of air represents only the first moments of the age spectrum, and thus gives no information of higher moments or variability on shorter time scales (Hall et al., 1999). To evaluate the old and new mass flux processing methods, we therefore compared the modeled mean age of air with long-term mean observations only. Such data were derived from a 7-year average in situ $\mathrm{CO}_{2}$ data record, sampled on board the ER-2 aircraft (Andrews et al., 2001).

\subsubsection{Comparison with observations}

Figure 1 shows the zonally-averaged mean age of air at $20 \mathrm{~km}$ from both model simulations (with the old and new mass fluxes) and the observed mean age of air at $20 \mathrm{~km}$ altitude. The mean age derived with the old winds is significantly too small in the extra-tropics, an earlier recognized problem that exists in many CTMs (Hall et al., 1999). The new method results in a mean age that is much closer to observations in the extra-tropics and illustrates a serious impact of the processing method. In the tropical region the air becomes somewhat older. Nevertheless, the calculated mean age of air remains too young in the extra-tropics.

\subsection{Ozone tracer experiment}

This model version of TM3 contains an ozone tracer with prescribed ozone production and first- and second-order loss rates from a stratospheric 2-D model (Pitari et al., 1993). The tracer is constrained by an ozone climatology (Fortuin and Kelder, 1998) down to $50 \mathrm{hPa}$, scaled with 1996 Global Ozone Monitoring Experiment (GOME) total ozone column data. More details of this version is given by Bregman et al. (2001). The studied year is 1996 and we will focus on the northern midlatitude UTLS (upper troposphere and lower stratosphere).

Instantaneous 3-D model ozone fields have been compared with two sets of observations. One set contains ozone pro- files from three ozone sounding stations (Hohenpeissenberg, Wallops Island, and Churchill), taken from the World Ozone Ultraviolet Radiation Data Centre (WOUDC) at the Meteorological Service of Canada. The second data set includes ozone data from the two most frequently flown MOZAIC flight tracks in the northern midlatitudes, namely Frankfurt - New York (FRA-NEW) and Vienna - Tokyo (VIE-TOK) (Marenco et al., 1998). To compare the model results with the MOZAIC observations, seasonally averaged flight tracks were created and the model ozone fields were interpolated to the aircraft location and pressure. The processing and comparison procedures have been developed by $\mathrm{H}$. Teyssèdre et al. [Personal Communication] and applied in Bregman et al. (2001).

\subsubsection{Comparison with observations}

Figures 2, 3 and 4 show results from comparisons with seasonally averaged ozone profiles from Wallops Island, Hohenpeissenberg, and Churchill. The calculated profiles using the old method are the same as shown in Bregman et al. (2001). The new method yields significantly better agreement for the whole potential temperature $(\theta)$ range shown and at all three stations, especially at Churchill. The best agreement is found between $\theta$ levels of 330-370 K. Outside this layer considerable deviations remain, which probably illustrates the limitations of using a parameterized ozone chemistry scheme in the model. Both at higher and lower $\theta$ levels photochemistry may play a more important role. In addition, uncertainties in the convection parameterization and the limited model grid resolution may become more critical in the upper troposphere.

Figures 5 and 6 show the results of a comparison between seasonally averaged model ozone mixing ratios +/one sigma $( \pm 1 \sigma)$ and MOZAIC observations for the 'mean' flight FRA-NEW and VIE-TOK. The dashed lines represent the results when the old processing method is applied and are the same as the solid red lines in Plates 2 and 3 in Bregman et al. (2001). In Bregman et al. (2001) several CTMs and GCMs participated in a model intercomparison with the same model setup for the ozone integrations as in this study. The flight track VIE-TOK is chosen because all models showed significant disagreement with observed mean mixing ratios and variability (the latter especially in summer) (Bregman et al., 2001).

A remarkable result is the excellent overall agreement for both mixing ratios and variability when the new processing method is used (solid lines). The large overestimate in all seasons, except for summer, has now disappeared. Even in summer the observed variability is well represented by our model. 

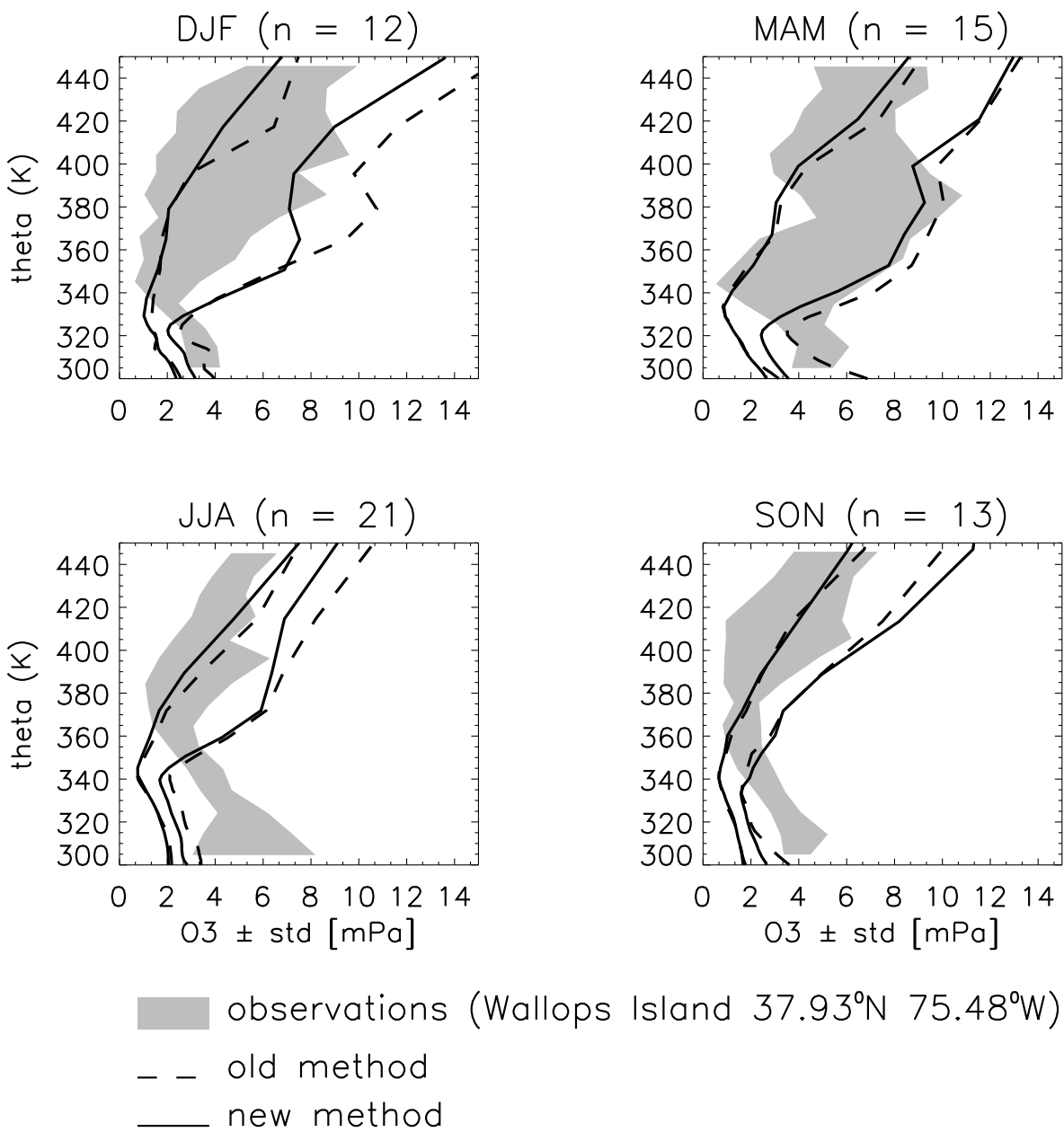

Fig. 2. Seasonal mean ozone partial pressure $(\mathrm{mPa}) \pm 1 \sigma$ from ozone sonde observations (filled grey) at Wallops Island. The dashed and solid lines represent the model results using the old and new mass flux processing method, respectively. The vertical axis is represented by the potential temperature $[\mathrm{K}]$.

\subsection{Analysis of the vertical mass fluxes}

To explain the differences between the model results using both processing methods we have analyzed the vertical mass fluxes. Figure 7 shows the zonal and annual mean vertical mass flux and standard deviation at 500, 200 and $100 \mathrm{hPa}$ between $80 \mathrm{~S}$ and $80 \mathrm{~N}$. At $500 \mathrm{hPa}$ differences in the mean mass flux are small, as can be expected from the old correction procedure, which contains a mass-weighted correction factor. Since maximum divergence is often found around $500 \mathrm{hPa}$, the correction is biased towards this pressure level. At $200 \mathrm{hPa}$ the old winds contain stronger upward transport in the tropical region and stronger downward transport in the subtropical jet streams. This explains the older air in the tropical region using the new winds. At lower pressure levels the magnitude of the mass fluxes become much smaller, and so are the differences in the mean mass fluxes. However, the mass flux variability changes significantly, which will be discussed below.
Older tropical air could also have been caused by enhanced lateral mixing with older extra-tropical air. However, given the steeper latitudinal gradient, enhanced meridional mixing does not seem to be present in the new winds. The meridional gradient, calculated with the new winds, remains nevertheless less steep than observed, indicating that the exchange between the tropics and extra-tropics may still be too strong. This has been found in other CTMs (Hall et al., 1999).

Note further that by using the meteorology of one particular year (1996), the calculated mean air age in the (sub)tropics may be underestimated, since the quasi-biennial oscillation (QBO) was in its easterly phase (Baldwin et al., 2001). On the other hand, the inter-annual variability of the age of air in the tropics is basically unknown, given the very limited observations (Waugh and Hall, 2003).

The winds derived by the old method most likely caused too much 'ventilation' or vertical mixing, an earlier reported shortcoming in CTMs (Schoeberl et al., 2002). Figure 7 indicates that vertical mixing is less pronounced using the new 

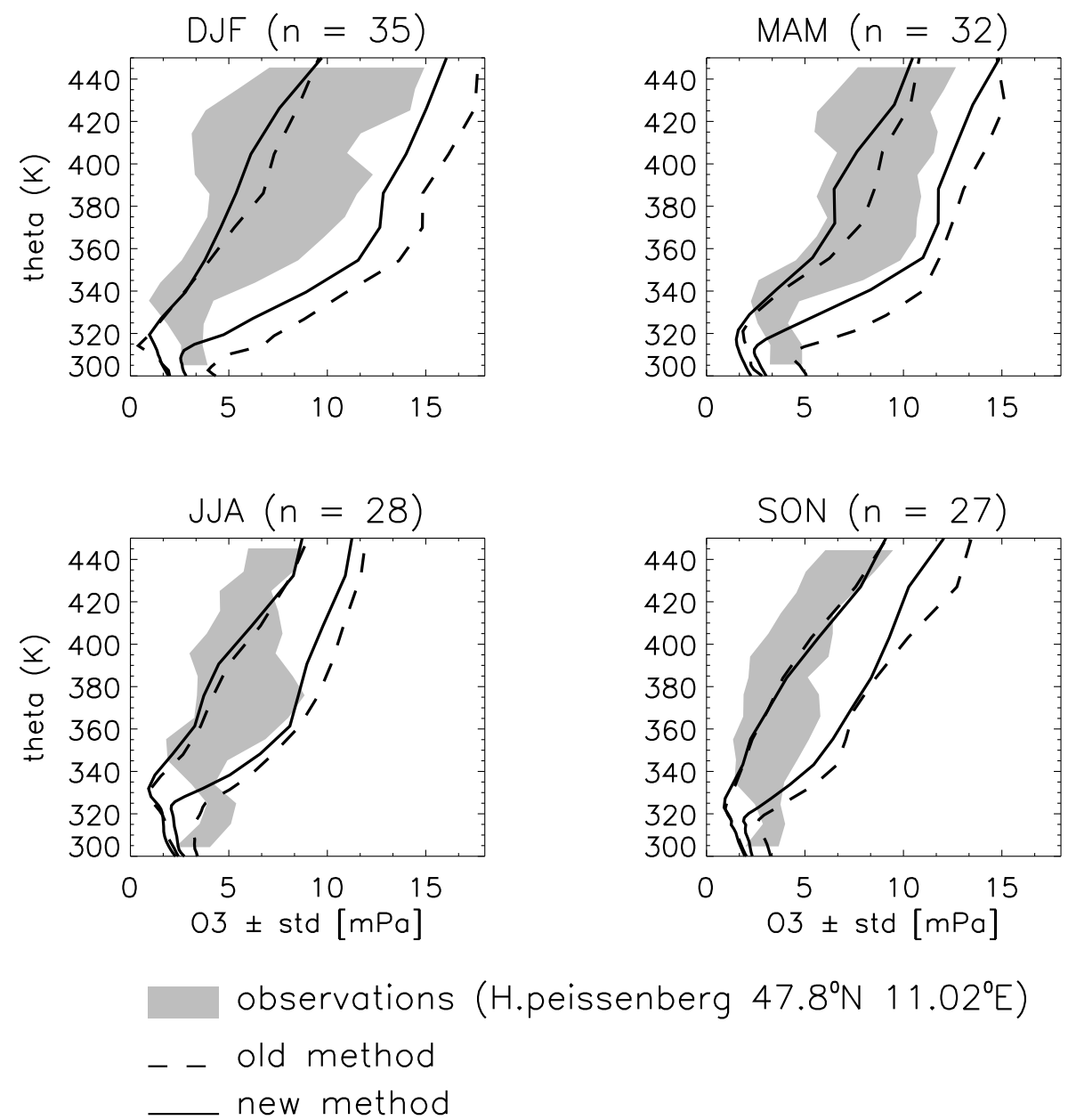

Fig. 3. Similar to Fig. 2, but for Hohenpeissenberg.

processing method and thus leads to an older mean age of air. In addition, the calculated mass flux variability is closer to reality, as will be discussed below, which also contributes to improved representation of the mean age of air.

Figure 7 shows that the new winds yield slighty larger variability of the vertical mass flux in the (sub)tropics, while it is significantly less in the old winds at middle and at high latitudes, especially at 200 and $100 \mathrm{hPa}$. For the ozone distribution in the tropopause region the vertical mass flux variability is an important quantity as will be shown below.

The main causes for the differences in vertical mass flux variability between both methods are (i) interpolation of spectral data to a Cartesian grid and (ii) a mass correction by applying a distribution function based on the total vertically integrated mass. In the new method the surface pressure tendency is taken into account in the mass balance equation for every vertical model layer. The old processing method therefore may introduce enhanced spurious variations in the vertical mass fluxes.

The weight of the interpolation errors increase when the grid cells become smaller, explaining the large increase of vertical mass flux variability closer to the poles with the old winds. By better representation of the winds the new method improves the 'real' mass flux variability. This is the most likely reason for the larger vertical mass flux variability in the tropical region using the new winds. The more realistic representation of mass flux variability is illustrated below.

Figure 8 shows the vertical mass flux variability $(2 \sigma)$ at 500,200 and $100 \mathrm{hPa}$ for the winter period along all longitudes at $50 \mathrm{~N}$. As shown for the zonal mean in Fig. 7, the old fluxes show larger variations than the new fluxes. A notable result in Fig. 8 is the much clearer manifestation of orography, and the North-Atlantic and Pacific storm tracks when applying the new method. Two distinct sharp maxima are present in the new fluxes indicating orographic effects, associated with the Rocky Mountains and the Himalayas. Also the North-Atlantic and Pacific storm tracks are somewhat more pronounced in the new winds. In reality orography and storm tracks induce enhanced vertical motion. The new method resolves this enhancement more accurate since the 

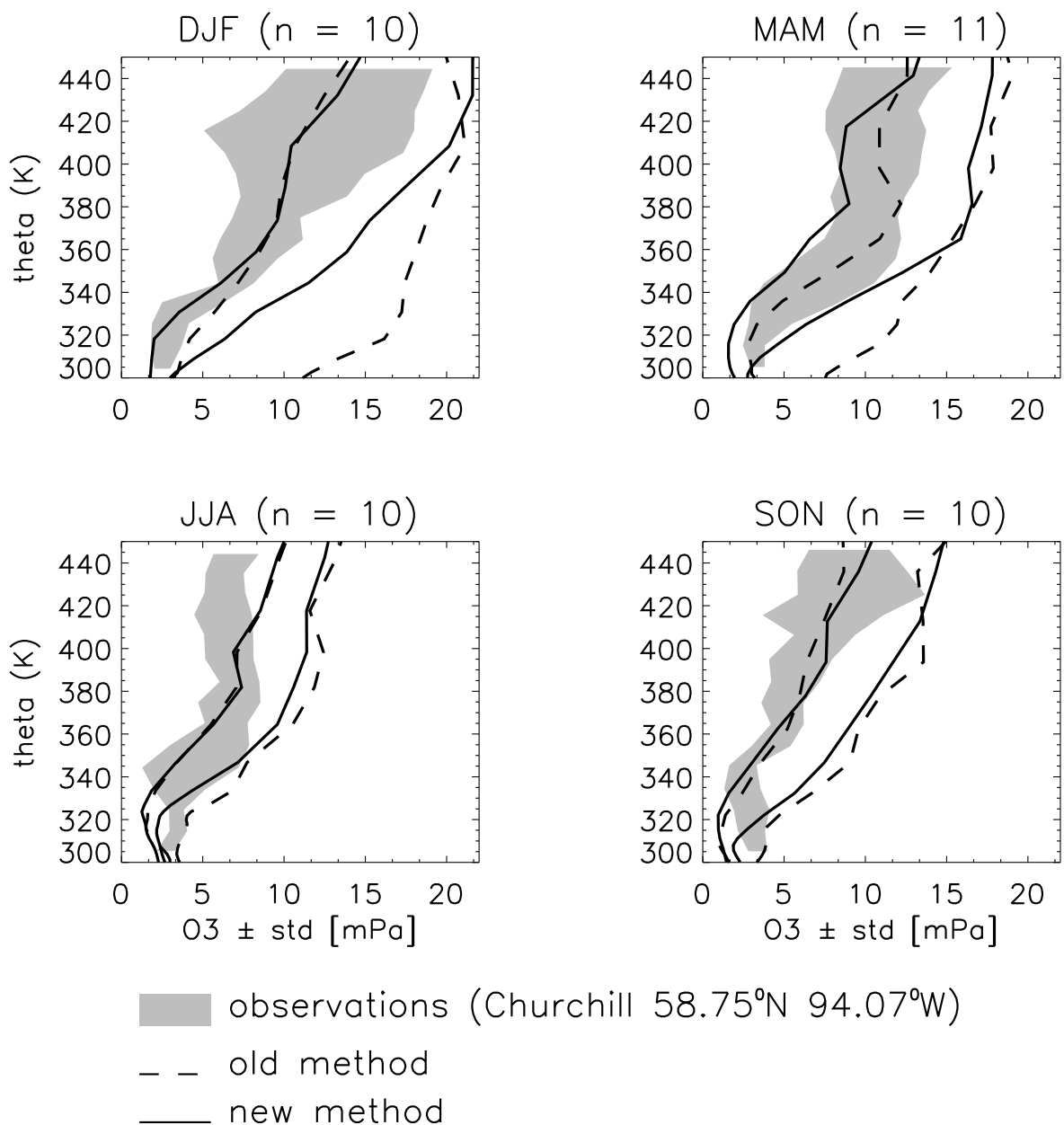

Fig. 4. Similar to Fig. 2, but for Churchill.

mass flux corrections are performed per vertical layer independent from the other layers. In the old method the corrections are equally distributed in the vertical, leading to smearing out of the variability.

The important role of the vertical mass flux variability for modeled ozone is further illustrated by comparing winter with summer. In contrast to the winter situation, in summer (see Fig. 9) the differences in mass flux variability between both methods are small, and so are the differences between modeled ozone distributions (see Figs. 2a and b). Hence, it seems that the difference in mass flux variability between both processing methods correlates with the differences in modeled ozone.

The observations for the MOZAIC flights were made close to the bottom edge of the large vertical ozone gradient near the tropopause. Fluctuations of the vertical mass flux will therefore lead to a net downward transport of ozone. This is the main reason for the large overestimation of ozone in the lowermost stratosphere when the old mass fluxes are used. Note that the annually average global downward ozone flux across the $150 \mathrm{hPa}$ level is reduced from about $1700 \mathrm{Tg} \mathrm{yr}^{-1}$ (Bregman et al., 2001) to $850 \mathrm{Tg} \mathrm{yr}^{-1}$. The latter flux is much better in agreement with estimates from observations reported in other studies (Murphy and Fahey, 1994).

Although in principle the new method applies to all models, the difference between the old and new method increases when the vertical levels are of a hybrid $\sigma$-pressure character. Nevertheless, it is important to note that even at fixed pressure levels $(100 \mathrm{hPa})$ the mass flux variability is improved (see Figs. 7 and 8).

\section{Conclusions}

A new mass flux processing method has been developed for chemistry-transport models. The method provides improved tracer-mass conserving wind fields, which solves the "massinconsistency' problem, reported in earlier model studies. It takes into account the imbalance of the mass budget for every grid cell and corrects it through adjustment to the horizontal mass fluxes. 

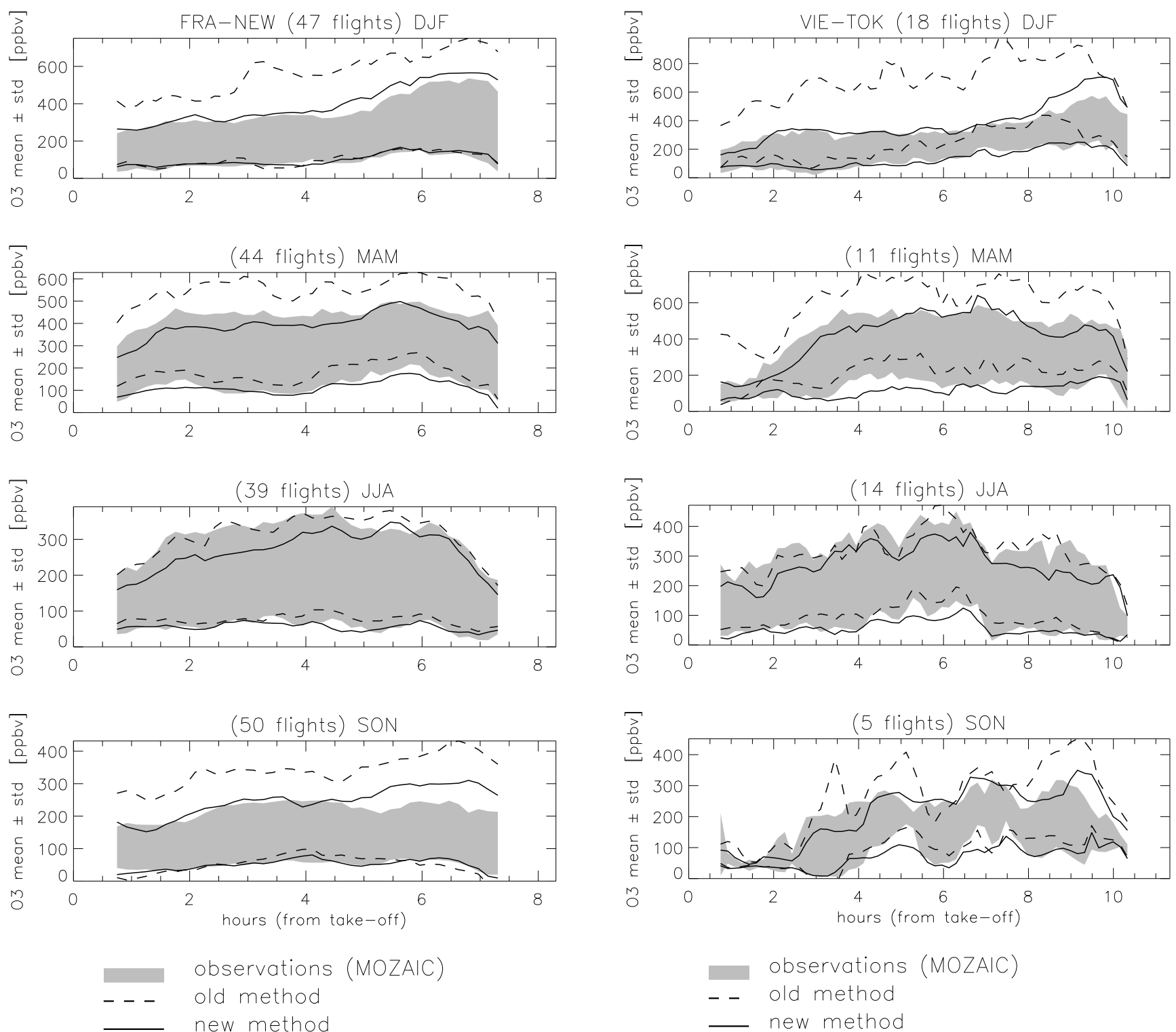

Fig. 5. Seasonal mean ozone mixing ratios (ppbv) $( \pm 1 \sigma)$, as observed during the MOZAIC project for the flight Frankfurt New York (filled grey), and calculated by the model using the old (dashed) and the new (solid) mass flux processing method.

Two different versions of the TM3 model, a 3-D CTM with ECMWF meteorological fields to drive the transport, were used to evaluate the mass flux processing methods. One version contained an artificial tracer in a tracer-pulse experiment to calculate the mean age of air. The other version contained ozone as a tracer with a prescribed production and loss rates, constrained with an observed ozone climatology.

The calculated mean age of air and ozone distributions were compared with observations. The mean age of air is much better represented using the new mass fluxes, most likely caused by reduced vertical mixing. Nevertheless, the

Fig. 6. Similar to Fig. 5, but for the flight Vienna - Tokyo.

calculated mean age of air remains somewhat too young in the extra-tropical lower stratosphere. A potential cause is the limited representation of the large-scale stratospheric circulation when using a model top at $10 \mathrm{hPa}$. To investigate this, additional experiments with the new ECMWF re-analysis (ERA40) are currently underway.

The ozone distribution in the lower stratosphere shows better agreement with balloon observations, with the best agreement at $\theta$ levels between approximately $330-370 \mathrm{~K}$. Outside this height range deviations remained, probably due to the limitation of the use of prescribed ozone chemistry. A striking improvement and excellent agreement with MOZAIC observations was found for ozone in the northern midlatitude tropopause region in all seasons over all longitudes, both in 

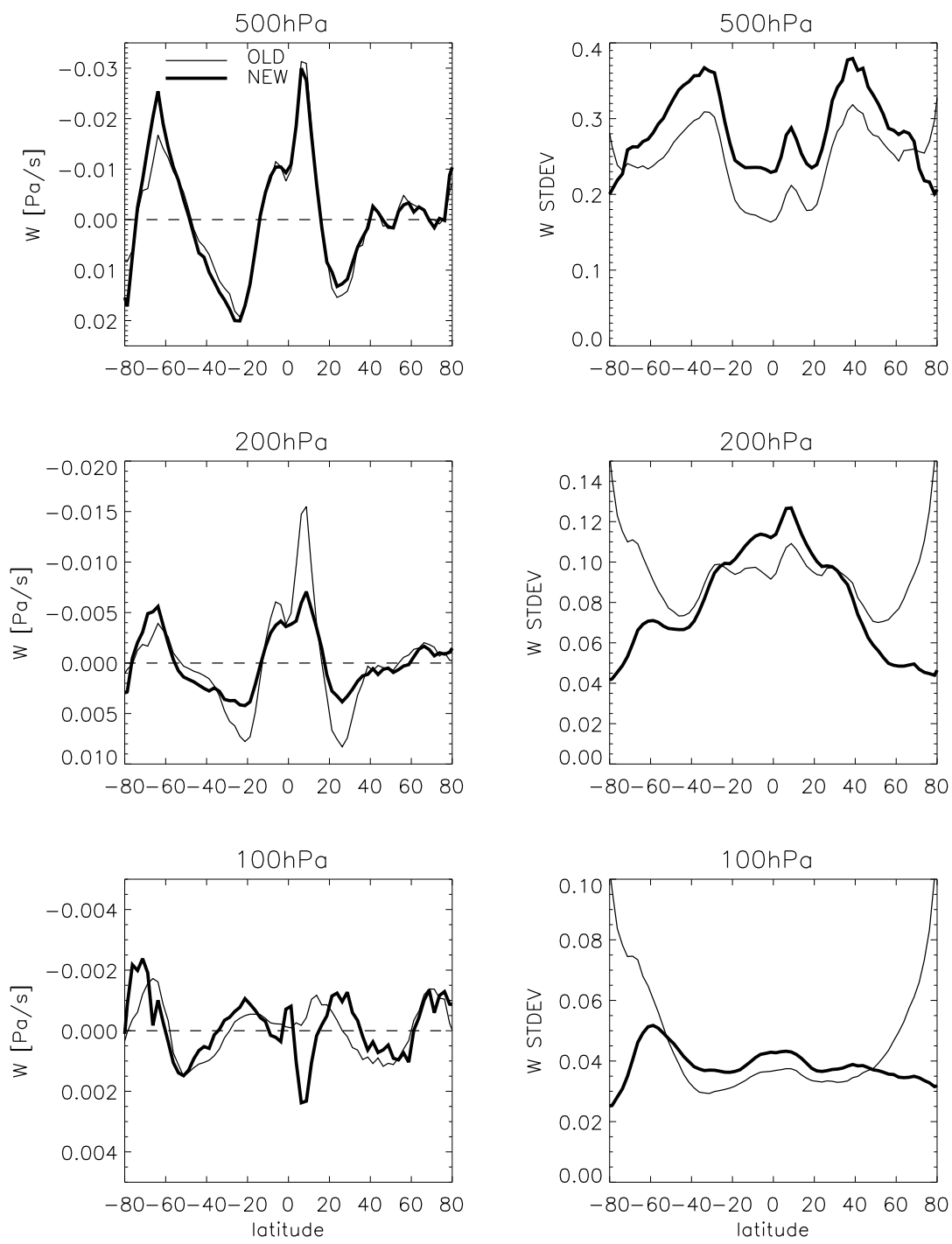

Fig. 7. Yearly and zonal mean vertical mass flux $\left(\mathrm{Pa} \mathrm{s}^{-1}\right)$ and standard deviation $( \pm 2 \sigma)$ calculated by the model at 100,200 and $500 \mathrm{hPa}$, using the old (thin solid lines) and the new (thick solid lines) mass flux processing method.

mean mixing ratios and variability.

By analyzing the vertical mass fluxes, most of the differences in modeled ozone and mean age of air between the old and the new processing methods could be explained. We have illustrated that the old mass flux processing method smooths out much of the real mass flux variability, while on the other hand it may create spurious variability. We have demonstrated that the model representation of the observations considerably improves when the mass fluxes contain less spurious and more realistic variability, even at fixed pressure levels.

The problems reported here are probably not restricted to models that use assimilated meteorological data to drive the transport. In many Eulerian climate models spectral wind fields are transformed into mass fluxes to perform the advection of tracers. For these models, as well as for off- line models, it is recommended that the vertically integrated mass divergence is made consistent with the surface pressure changes. All relevant terms, including $\nabla \ln p_{s}$, should be calculated using their spherical harmonic representation. Finally, a FORTRAN 90 code of the new processing algorithm is available at http://www.knmi.nl/ $\sim$ segers.

Acknowledgements. We are grateful to the MOZAIC and WOUDC community for the availability of the ozone data. We also thank Arlyn Andrews for the mean age of air data shown in Fig. 1. Very valuable comments were given by Martin Heimann, Philip Cameron-Smith, and an anonymous reviewer, that greatly improved the manuscript. The age of air model simulations have been performed in the framework of the EU-project TRADEOFF (contract EVK2-1999-00030). Part of this work is funded by the EU-project TOPOZ II (contract ENV4-CT97-0542) and TOPOZ III (contract EVK2-CT-2001-00102). 

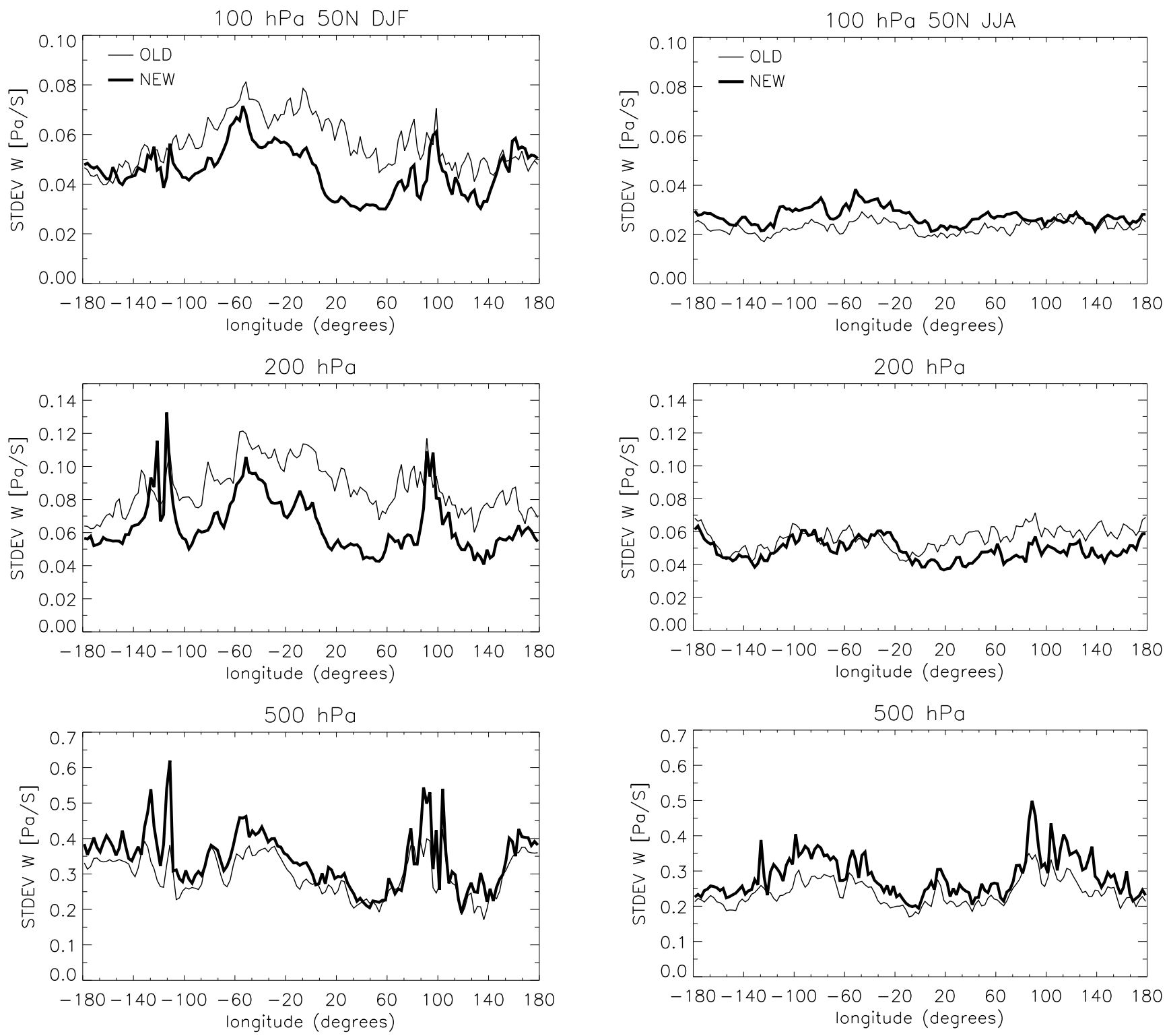

Fig. 8. Standard deviation $(2 \sigma)$ of the calculated vertical mass flux $\left(\mathrm{Pa} \mathrm{s}^{-1}\right)$ at $50^{\circ} \mathrm{N}$ and three different pressure levels (100, 200 and $500 \mathrm{hPa}$ ) in December, January, and February (DJF), using the old (thin solid lines) and the new (thick solid lines) mass flux processing method.

\section{References}

Andrews, A., Boering, K., Daube, B., Wofsy, S., Loewenstein, M., Jost, H., Podolske, J., Webster, C., Herman, R., Scott, D., Flesh, G., Moyer, E., Elkins, J., Dutton, G., Hurst, D., Moore, F., Ray, E., Romanshkin, P., and Strahan, S.: Mean ages of stratospheric air derived from in situ observations of $\mathrm{CO}_{2}, \mathrm{CH}_{4}$, and $\mathrm{N}_{2} \mathrm{O}$, J. Geophys. Res., 106, 32 295-32 314, 2001.

Baldwin, M., Gray, L., Dunkerton, T., Hamilton, K., Haynes, P., Randel, W., Holton, J., Alexander, M., Hirota, I., Horinouchi, T., Jones, D., Kinnersley, J., Marquardt, C., and Takahasi, M.: The 
Hall, T. and Waugh, D.: Timescales for the stratospheric circulation derived from tracers, J. Geophys. Res., 102, 8991-9001, 1997.

Hall, T., Waugh, D., Boering, K., and Plumb, R.: Evaluation of transport in stratospheric models, J. Geophys. Res., 104, 18 815$18839,1999$.

Heimann, M.: The Global Atmospheric Tracer Model TM2, Tech. Rep. 10, DRKZ-Hamburg, 1995.

Heimann, M. and Keeling, C.: A three-dimensional model of atmospheric $\mathrm{CO}_{2}$ transport based on observed winds: 2: Model description and simulated tracer experiments, Geophys. Mon., 55, 237-275, 1989.

Houweling, S., Dentener, F., and Lelieveld, J.: The impact of nonmethane hydrocarbon compounds on tropospheric photochemistry, J. Geophys. Res., 103, $10673-10696,1998$.

Jöckel, P., von Kuhlmann, R., Lawrence, M., Steil, B., Brenninkmeijer, C., Crutzen, P., Rasch, P., and Eaton, B.: On a fundamental problem in implementing flux-form advection schemes for tracer transport in 3-dimensional general circulation and chemistry transport models, Q. J. R. Meteorol. Soc., 127, 10351052, 2001.

Marenco, A., Thouret, V., Nedelc, P., Smit, H., Helten, M., Kley, D., Karcher, F., Simon, P., Law, K., Pyle, J., Poschmann, G., von Wrede, R., Hume, C., and Cook, T.: Measurement of ozone and water vapor by airbus in-service aircraft: The MOZAIC airborne program, an overview, J. Geophys. Res., 103, 25 631-25 642, 1998.

Murphy, D. and Fahey, D.: An estimate of the flux of stratospheric reactive nitrogen and ozone into the troposphere, J. Geophys. Res., 99, 5325-5332, 1994.

Peters, W., Krol, M. C., Dentener, F. J., and Lelieveld, J.: Identi- fication of an El Niño-Southern Oscillation signal in a multiyear global simulation of tropospheric ozone, J. Geophys. Res., 106, 10389-10 402, 2001.

Pitari, G., Rizi, V., Ricciardulli, L., and Visconti, G.: High-speed civil transport impact: Role of sulfate, nitric acid trihydrate, and ice aerosols studied with a two-dimensional model including aerosol physics, J. Geophys. Res., 98, 23 141-23 164, 1993.

Prather, M.: Numerical advection by conservation of second-order moments, J. Geophys. Res., 91, 6671-6681, 1986.

Schoeberl, M., Douglass, A., Zhu, Z., and Pawson, S.: A comparison of the lower stratospheric age-spectra, derived from a General Circulation Model and two data assimilation systems., Submitted to the J. Geophys. Res., 2002.

Segers, A., van Velthoven, P., Bregman, B., and Krol, M.: On the computation of mass fluxes for Eulerian transport models from spectral meteorological fields, in Proceedings of the 2002 International Conference on Computational Science, Lecture Notes in Computer Science (LNCS), Springer Verlag, 2002.

Simmons, A. and Burridge, D.: An energy and angular-momentum conserving vertical finite-difference scheme in hybrid vertical coordinates, Mon. Weather. Rev., 109, 758-766, 1981.

Stockwell, D. and Chipperfield, M.: A tropospheric chemicaltransport model: Development and validation of the model transport schemes, Q. J. R. Meteorol. Soc., 125, 1747-1783, 1999.

van den Broek, M., Bregman, A., and Lelieveld, J.: Model study of stratospheric chlorine and ozone loss during the 1996/1997 winter, J. Geophys. Res., 105, 28 961-28 977, 2000.

Waugh, D. and Hall, T.: Age of stratospheric air: theory, observations, and models, Reviews of Geophysics, in press, 2003. 